\title{
Community-associated MRSA: Superbug at our doorstep
}

\author{
Michael Hawkes, Michelle Barton, John Conly, Lindsay Nicolle, Clare Barry, Elizabeth L. Ford-Jones
}

W hile the potential for a devastating influenza pandemic has captured the imagination of the medical community and the population at large, another epidemic is currently raging in the United States and has already made inroads in Canada. ${ }^{1}$ Clones of communityassociated methicillin-resistant Staphylococcus aureus (CAMRSA) are spreading with alarming rapidity and are replacing methicillin-sensitive strains of $S$. aureus as the most common cause of skin and soft-tissue infection. Methicillin resistance among community isolates of $S$. aureus has already exceeded a staggering $70 \%$ in Houston ${ }^{2}$ and Atlanta ${ }^{3}$ and threatens to emerge in force north of the border. CAMRSA is an "old foe with new fangs" ing virulence, resistance and an ability to disseminate at large. ${ }^{5}$ Most CA-MRSA infections involve the skin and soft tissue; however, severe and sometimes fatal infections have been observed, including sepsis, necrotizing pneumonia, purpura fulminans, pyomyositis and necrotizing fasciitis, even in healthy patients. To address this urgent problem, new guidelines for the management and prevention of CAMRSA have been developed. ${ }^{6}$

\section{Why develop new Canadian guidelines?}

At present, the prevalence of CA-MRSA in Canada is unknown except for in I or 2 provinces that are conducting active surveillance for CA-MRSA. Based on the collective clinical experience of infectious disease experts across Canada, the prevalence is presently thought to be low, but to be rising in most sectors of the country. Outbreaks and isolated cases of CA-MRSA have been reported in Canada since the I980s, as shown in Table I. However, we are now concerned about the widespread dissemination and dominance of CA-MRSA in Canada, as has been observed in the United States. If Canada is to delay or prevent the emergence of CA-MRSA in its communities, vigilance and determined control efforts will be needed. Thus, these new guidelines for Canadians come at a critical time.

\section{Who are the guidelines for?}

The target audience, as well as the authorship, is truly multidisciplinary. The guidelines are directed toward health care workers, including front-line physicians, public health practitioners, laboratory personnel, nurses, infection control practitioners, veterinary medicine personnel and other health care workers participating in outbreak management and direct patient care.

\section{Key recommendations}

The treatment ${ }^{17}$ and public health ${ }^{18}$ aspects of CA-MRSA have been addressed previously; therefore, here we highlight the salient features of the new guidelines related to CA-MRSA prevention and control.

Transmission of CA-MRSA, as is the case for methicillinsensitive $S$. aureus, occurs through direct contact. The US Centers for Disease Control and Prevention summarize the modes of CA-MRSA transmission as the " 5 Cs" (Box I) ${ }^{19}$ Certain groups are disproportionately affected by CA-MRSA (Box 2), perhaps because of the prevalence of factors permissive for its transmission within these groups.

\section{Screening and decolonization}

Screening patients for colonization with MRSA has been used to direct infection control measures in hospital set-

Table 1: History of community-associated methicillin-resistant Staphylococcus aureus (CA-MRSA) in Canada

\begin{tabular}{|c|c|}
\hline Year & Canadian case or outbreak of CA-MRSA \\
\hline $1986-1989$ & $\begin{array}{l}\text { Multi-strain cluster in an Aboriginal community } \\
\text { in Alberta }{ }^{7}\end{array}$ \\
\hline 1997-1998 & $\begin{array}{l}\text { Cluster of skin and soft tissue infections in rural } \\
\text { Manitoba }^{8}\end{array}$ \\
\hline 1998 & $\begin{array}{l}\text { Case of disease and transmission in Toronto day } \\
\text { care }^{9}\end{array}$ \\
\hline $2000-2005$ & $\begin{array}{l}\text { Rapid emergence of an epidemic strain in } \\
\text { northern Manitoba and Saskatchewan }{ }^{10}\end{array}$ \\
\hline 2004 & $\begin{array}{l}\text { An estimated } 11 \% \text { of MRSA isolates in Ontario are } \\
\text { community acquired }{ }^{11}\end{array}$ \\
\hline 2004 & $\begin{array}{l}\text { Severe SSTI among illicit drug users and } \\
\text { homeless people in Calgary }\end{array}$ \\
\hline 2005 & $\begin{array}{l}\text { Fatal case of necrotizing pneumonia in a young } \\
\text { healthy adult in Calgary }{ }^{14}\end{array}$ \\
\hline 2005 & $\begin{array}{l}\text { Fatal case of necrotizing pneumonia and sepsis } \\
\text { in a 3-month-old infant in Toronto }{ }^{15}\end{array}$ \\
\hline 2005 & $\begin{array}{l}\text { Additional cases of severe necrotizing } \\
\text { pneumonia in Southern Alberta }{ }^{16}\end{array}$ \\
\hline
\end{tabular}


Box 1: The " $5 \mathrm{Cs}$ " implicated in transmission of community-associated methicillin-resistant Staphylococcus aureus (CA-MRSA) ${ }^{19}$

- Crowding

- frequent skin Contact

- Compromised skin

- sharing Contaminated personal care items

- lack of Cleanliness

tings, but screening is less relevant in the community at large. In a recent US population-based survey, colonization with MRSA was detected in only $0.84 \%$ of the noninstitutionalized population..$^{20}$ At present, there is insufficient evidence to support the use of eradication regimens, ${ }^{21}$ and therefore little reason to screen asymptomatic individuals. In exceptional situations, such as recurrent infections in a patient or within a family, or during an outbreak, screening for carriage of CA-MRSA and decolonization of carriers may be attempted. For eradication or reduction of CA-MRSA from carriers, some experts favour a combined approach (including intranasal mupirocin, topical antiseptics and 2 systemic agents), although other experts recommend the use of intranasal mupirocin alone.

\section{Surveillance}

Surveillance for methicillin resistance among community associated strains of $S$. aureus should be considered in order to direct empiric therapy of skin and soft-tissue infections, which may need to be modified if CA-MRSA rates increase. Groups recognized to be at high risk (Box 2) should be a particular focus of surveillance programs. Monitoring CA-MRSA in the community will require collaboration among clinicians, microbiology laboratories and public health departments.

\section{Prevention}

The goal of community control is to prevent the spread of CAMRSA from an infected or colonized individual to others in the family or community. Individuals will need to take a proactive role: practising good hygiene, including consistent hand washing, covering any draining skin lesions and not sharing potentially contaminated personal articles. Physicians have a role to play in preventing the spread of CAMRSA, by educating their patients (e.g., encouraging good personal hygiene practices), notifying public health authorities in the case of a suspected outbreak and by restricting the unnecessary use of antibiotics because this drives the selection of antibiotic-resistant organisms. Health authorities may also contribute by instituting education programs targeting physicians and individuals within the community, particularly those in high-risk groups, and by creating local programs to review antibiotic use and resistance. Of note, these control measures are not specific to CA-MRSA, and may also limit the spread of other organisms transmitted by direct contact. The
Box 2: Populations at increased risk of communityassociated methicillin-resistant Staphylococcus aureus

- Children less than 2 years old

- Minority populations:

- Native or Aboriginal

- African-American

- Athletes (mainly contact-sport participants)

- Injection drug users

- Men who have sex with men

- Military personnel

- Inmates of correctional facilities

- Veterinarians, pet owners and pig farmers

Canadian guidelines address prevention and control measures in several specific situations that are summarized below:

\section{Households affected by CA-MRSA}

Within homes where CA-MRSA infection is detected, standard household cleaning products are adequate for cleaning the environment and washing the laundry, utensils and dishes.

\section{Day-care centres and schools}

Isolation of children with CA-MRSA in day-care centres or schools is not a practical solution and has a negative affect on the child's well-being. Instead, hygienic measures within the day care or school should be emphasized in order to reduce the risk of transmission (e.g., hand hygiene, respiratory etiquette, staying home if ill). Hand washing can be promoted by ensuring the availability of products such as alcohol gel, and structuring activities to include opportunities for hand hygiene to be practised (e.g., before eating, after outdoor play). In addition, washing hands with soap and water after toilet use is to be encouraged. If a child has a draining wound that cannot be consistently covered, the child may be excluded from day care or school until wound healing occurs.

\section{Sports settings}

CA-MRSA transmission has been documented in several reports among athletes and those who participate in contact sports. ${ }^{6}$ Hygiene measures should be reinforced in this highrisk group, including using alcohol gel for hand hygiene when sinks are not available, showering after every practice or tournament, avoiding the sharing of towels and other personal-care items, regular cleaning of communal bathing areas, and cleaning or laundering of equipment (ideally after every use). Athletes with draining lesions that cannot be adequately covered should not share athletic equipment that is in contact with the skin, should not participate in contact sports and should be excluded from common whirlpools or saunas until the wound has healed or drainage can be contained. 


\section{Pets and other animals}

Recurrent MRSA infections in household contacts of colonized pets have been described. ${ }^{6}$ Veterinarians and physicians should be aware of pets as a possible reservoir for infection. Indeed, physicians should inquire about pet ownership and document MRSA carrier status if known. Routine screening and decolonization of pets is not indicated.

\section{Correctional facilities and shelters}

Outbreaks of CA-MRSA have been documented in incarcerated populations in the United States and in Canada. ${ }^{6}$ Staff and inmates should be educated about the transmission, prevention, treatment and containment of CA-MRSA infections. In cases where an inmate has an uncovered draining skin lesion or poor hygiene, restricting their contact with others should be considered to prevent the exposure of other inmates.

\section{Can this superbug be stopped at the border?}

Recommendations for prevention at the community level come in the face of a growing pessimism among Canadian experts, some of whom feel that the replacement of methicillinsensitive strains of $S$. aureus by CA-MRSA is inevitable, ${ }^{17}$ and that at least in the United States the "horses may have already left the starting gate." ${ }^{18}$ Taking a page from history, the emergence of methicillin-resistant $S$. aureus recapitulates the story of penicillin-resistant $S$. aureus, which first spread in hospitals and then in the community, so that few physicians today would consider prescribing penicillin for the treatment of a skin and soft-tissue infection. ${ }^{22}$ Perhaps the remaining $\beta$-lactam antibiotics are only the latest in a series of hurdles for $S$. aureus as it evolves in the context of antibiotic selection pressure.

Front-line physicians need to be aware of the increasing prevalence and the potential severity of CA-MRSA infection. They are referred to the new Canadian guidelines for further information, and for management strategies for CA-MRSA. ${ }^{6}$ Physicians have a key role to play in attenuating CA-MRSA transmission by educating patients, promoting good hygiene practises and limiting antibiotic use. Although the CA-MRSA superbug is advancing northward and is knocking at our door, it is prudent to take every preventive effort not to welcome it inside our borders.

\section{This article has been peer reviewed.}

Michael Hawkes, Michelle Barton and Elizabeth Ford-Jones are with the Department of Infectious Diseases, The Hospital for Sick Children, Toronto, Ont.; John Conly is with the Department of Medicine, University of Calgary, Calgary, Alta.; Lindsay Nicolle is with the Department of Infectious Diseases, University of Manitoba, Winnipeg, Man.; Clare Barry is with the Ministry of Health and Long-Term Care, Toronto, Ont.
Competing interests: None declared.

Acknowledgement: We thank Jane McIvor for her help in preparing this manuscript.

\section{REFERENCES}

I. Moellering RC Jr. The growing menace of community-acquired methicillin-resistant Staphylococcus aureus. Ann Intern Med 2006;I44:368-70.

2. Kaplan SL, Hulten KG, Gonzalez BE, et al. Three-year surveillance of communityacquired Staphylococcus aureus infections in children. Clin Infect Dis 2005;40:1785-9I.

3. King MD, Humphrey BJ, Wang YF, et al. Emergence of community-acquired methicillin-resistant Staphylococcus aureus USA300 clone as the predominant cause of skin and soft-tissue infections. Ann Intern Med 2006;144:309-I7.

4. Hinrichs JH. CA-MRSA: An old foe develops new fangs. Mo Med 2006;103:129-32.

5. Chambers HF. Community-associated MRSA-resistance and virulence converge. $N$ Engl J Med 2005;352:1485-7.

6. Barton-Forbes M, Hawkes M, Moore D, et al. Guidelines for the prevention and management of community associated methicillin resistant Staphyococcus aureus (CA-MRSA): a perspective for Canadian health care practitioners. Can J Infect Dis and Med Microbiol 2006; 17 (Suppl C): IB-24B.

7. Taylor G, Kirkland T, Kowalewska-Grochowska K, et al. A multistrain cluster of methicillin-resistant Staphylococcus aureus based in a Native community. Can J Infect Dis 1990;I:I2I-6.

8. Kurbis, Wylie. Community-based cluster of methicillin-resistant Staphylococcus aureus in Manitoba. Can J Infect Dis 200I.;12:I49-52.

9. Shahin R, Johnson IL, Jamieson F, et al. Methicillin-resistant Staphylococcus aureus carriage in a child care center following a case of disease. Toronto Child Care Center Study Group. Arch Pediatr Adolesc Med I999;153:864-8.

Io. Wylie JL, Nowicki DL. Molecular epidemiology of community- and health care-associated methicillin-resistant Staphylococcus aureus in Manitoba, Canada. J Clin Microbiol 2005;43:2830-6.

II. McGeer A, Fleming CA, Green KA, et al. Changes in antimicrobial resistance in Ontario hospitals. Quality Management Program Laboratory Services. 2005. Available: www.qmpls.org/pub_resources/publications/qmpls_news/pdf/qmpls newso89.pdf (accessed 2006 Nov 17).

I2. Gilbert M, MacDonald J, Gregson D, et al. Outbreak in Alberta of community-acquired (USA300) methicillin-resistant Staphylococcus aureus in people with a history of drug use, homelessness or incarceration. CMAJ 2006;175:149-54.

I3. Gilbert M, Siushansian J, Macdonald J., et al. An outbreak of the USAzoo strain of community-acquired methicillin-resistant Staphylococcus aureus CMRSA infections in individuals with histories of drug use, homelessness or incarceration. Can J Infect Dis Med Microbiol 2005; 16:108.

I4. Conly J, Gilbert M, Zhang K, et al. Rapidly Progressive Fatal Necrotizing Pneumonitis secondary to Panton-Valentine Leukocidin PVL positive, SCCmec Type IVa Community-Acquired Methicillin-Resistant $S$ aureus CAMRSA - A Harbinger of the Future. Can J Infect Dis Med Microbiol 2005; 6:Io9.

15. Brophy J, Yau Y, Cox P, et al. Sentinel case of pediatric CA-MRSA in Canada. Paediatrics and Child Health. In press.

I6. Janvier J, Elsayed S, Gregson D., et al. Necrotizing Pneumonia Secondary to CAMRSA USAzoo Strain Without Evidence of Antecedent Upper Viral Respiratory Infection. Can J Med Micro Infect Dis 2006;17:30.

I7. Nicolle L. Community-acquired MRSA: a practitioner's guide. CMAJ 2006;175:I45

I8. Allen UD. Public health implications of MRSA in Canada. CMAJ 2006;I75:I6I.

I9. Gorwitz RJ, Jernigan DB, Powers JH, et al. Strategies for clinical management of MRSA in the community: Summary of an experts' meeting convened by the Centers for Disease Control and Prevention. 2006. Available: www.cdc.gov/ncidod /dhqp/pdf/ar/CAMRSA_ExpMtgStrategies.pdf (accessed 2006 Nov I7).

20. Graham PL III, Lin SX, Larson EL. A U.S. population-based survey of Staphylococ cus aureus colonization. Ann Intern Med 2006;144:318-25.

21. Loeb M, Main C, Walker-Dilks C, et al. Antimicrobial drugs for treating methicillin-resistant Staphylococcus aureus colonization. In: The Cochrane Library; Issue 4, 2003. Oxford: Update Software.

22. Chambers HF. The changing epidemiology of Staphylococcus aureus? Emerg Infect Dis 2001; 7:178-82.

Correspondence to: Dr. John Conly, Department of Medicine, University of Calgary, Room 930 North Tower, Foothills Medical Centre, I403 2gth St. NW, Calgary AB T2N 2T9; fax 403 944ro95; john.conly@calgaryhealthregion.ca 